\title{
Consequences of information covering the COVID-19 pandemic from the point of view of Terror Management Theory
}

\author{
Polina Dmitrieva* \\ Southern Federal University, 344006, Rostov-on-Don, Russia
}

\begin{abstract}
The article is devoted to the description and explanation of individual psychological and social phenomena from the point of view of actualizing thanatic issues during the COVID-19 pandemic and its information coverage. The relevance of the study is due to the situation of the spread of coronavirus infection, the peculiarities of combating its spread, the influence of information technologies on this process and the need to understand the phenomena that have developed in society. The novelty of the research lies in the complex consideration of various social and individual psychological phenomena from the standpoint of the influence of the vital threat and existential fears on the individual and social consciousness. The article contains information on the sociopsychological phenomena that manifested themselves during the COVID19 pandemic (alarmism, infodemic, intergroup tensions, stigmatization of certain groups of the population, a shift in political preferences, aggravation or emergence of mental disorders, inadequate purchasing activity) and describes them in terms of Terror Management Theory. In the conclusion, prospects are given for using the provisions of Terror Management Theory to develop a strategy for overcoming a pandemic situation, taking into account the action of proximal and distal defenses. The author comes to the conclusion that the features of the information coverage of the situation have a strong influence on its further development, in connection with which it is necessary to develop a clear plan for the preparation of official information that meets the criteria of completeness, credibility, scientific character and conveys the idea of positive realism.
\end{abstract}

\section{Introduction}

The COVID-19 pandemic has had a tremendous impact on human life. This event, unprecedented in scale and methods of struggle, has put humanity in front of the need to take the most radical measures, sacrificing freedom and rights in the name of universal security. The ban on travel, the obligation to comply with preventive measures, the use of masks and gloves, the inability to return to their homeland due to the introduction of quarantine measures, the transfer of most processes to the online mode is a far from

\footnotetext{
*Corresponding author: pmamedova@sfedu.ru
} 
complete list of what has become everyday in 2020. At the same time, the media and social networks have played a special role in the course of the pandemic and in taking measures to combat the infection. The availability of information, the speed and ease of its transmission shaped public opinion and behavior, which developed spontaneously under the influence of official and private, scientific and pseudoscientific, false and truthful information. This gave rise to the phenomenon of the so-called "infodemic", which often undermined the activities of government agencies to suppress the spread of coronavirus infection and led to an overload of healthcare systems.

The consequences of the pandemic are obvious - a drop in the level of health of the population, an increase in mortality, disruption of economic processes and industries that sometimes cannot be restored, a decrease in the level of well-being of the population, an increase in the number of conflicts in families due to the forced stay in a confined space for a long time, unemployment, suicidal behavior and alcoholism. Nevertheless, the awareness of the vital threat and the fear of death actualized by it, entailed other processes in society that were not directly related to the coronavirus, but got the opportunity to be deployed due to extreme situations in which humanity found itself. These processes include: alarmism, intergroup tension, stigmatization of certain groups of the population, a shift in political preferences, aggravation or occurrence of mental disorders, inadequate purchasing activity.

These processes can be explained from the position of the theory of managing the fear of death in view of the fact that it is death and the preservation of life that become the center of mass consciousness during a pandemic. The statistics of infection, mortality and recovery rates are becoming an integral attribute of most sites, constantly updating thanatic issues and thoughts about death among users. At the same time, direct and indirect reminders of death trigger specific mechanisms of psychological defense, which are reflected in a perverted form in the processes indicated above.

Thus, the purpose of this article is to describe and explain a number of individual psychological and social phenomena from the point of view of actualizing thanatic issues during the COVID-19 pandemic and its information coverage.

The carried out analysis can help in understanding the processes that were observed during the pandemic and the reasons that led to them. This can provide significant assistance in developing a strategy for ending the pandemic situation, the stages of getting out of the lockdown, and lifting quarantine measures. In addition, an analysis of the nature of the described phenomena can form the basis for developing an action plan in the event of a repetition of situations to minimize negative manifestations.

\section{Methods}

One of the most developed concepts describing the influence of attitude towards death on society in general and the individual in particular is the socio-psychological Terror Management Theory (TMT), proposed by Greenberg, Solomon, Pischinski (1992) based on the works of the cultural anthropologist E. Becker [1]. According to this theory, there are two buffers that help a person cope with the horror of realizing his own death: the cultural picture of the world and self-esteem. The cultural picture of the world includes ideas about the world, accepted in a given society, including religious beliefs and values. The separation of these values and ideas gives a person a sense of "symbolic immortality", which reveals the idea that after the physical death of a person, they will continue to exist in the form of essences and values accepted in a given society. Self-esteem corresponds to the subjective degree of compliance with the cultural picture of the world, involvement in society. According to TMT, it is the fear of death that prompts a person to socially acceptable behavior and the desire to leave a mark about himself in the products of creativity, raising children, and the results of work. 
In the context of highlighting the problems of this article, the model of a double process is of particular interest. It is it, which is triggered at the reminder of death and includes the proximal and distal defense mechanisms against the horror of realizing one's own mortality.

The main sense of the proximal defense is to actively counteract death - suppressing thoughts about it, denying one's own mortality, avoiding information, trying to prevent its occurrence. It starts when thoughts about death fall into the focus of consciousness. When thoughts about death are not conscious, distal defenses work, aimed at strengthening protective buffers - the cultural picture of the world and self-esteem.

The theory of managing fear of death has a broad evidence base, but most of the research has been conducted in a laboratory setting. The situation of the pandemic has put humanity in the face of death, in connection with which we are faced with a variety of socio-psychological phenomena that can be explained from the point of view of TMT in real conditions.

Thus, the theoretical basis of the study was the most developed concept describing the attitude towards death - the theory of managing the fear of death, as well as data from theoretical and empirical studies conducted by domestic and foreign scientists describing the phenomenon of the COVID-19 pandemic, its coverage in the media and their impact on the individual and society.

\section{Results}

The results of the analysis of the scientific literature of the humanitarian spheres of knowledge made it possible to identify a number of individual psychological and social phenomena generated by the pandemic and endowing it with specific characteristics and likely negative consequences for society. The following can be attributed to the group of social phenomena: alarmism and panic in the information field, called "infodemia", intergroup tension, stigmatization of certain groups of the population, shifts in political preferences towards charismatic leaders and conservative values. The consequences of these phenomena in the individual psychological plan, first of all, were the aggravation of the condition of people suffering from mental disorders, and the occurrence of such in people who do not suffer from mental disorders, the emergence of the Internet addiction, and inadequate purchasing activity.

We are to describe the observed phenomena from the point of view of actualizing the problem of death in view of the objective situation of threat to life and health and its coverage in the information field. The influence of the mass media is conditioned, on the one hand, by the speed of information transmission, on the other hand, by the very actual conditions in which most of the world's population found itself due to the introduction of a lockdown, when information technologies have sometimes become the only means of communication with society. This entailed a number of consequences in social life and the life of an individual.

\subsection{Alarmism and panic in the information field, the so-called "infodemy"}

The World Health Organization (WHO) calls infodemia "an overabundance of offline and online information" [2], including the deliberate use of false and inaccurate information. WHO identifies the possible consequences of infodemics: "harm to the physical and mental health of people, increased stigmatization, a threat to major healthcare achievements, disregard for measures to protect public health, polarization of public opinion, the spread of hate speech, disunity of people" [2].

Alarmism in this case acts as one of the brightest manifestations of infodemia, which made it possible to spread unverified information and private opinions at lightning speed 
under the guise of official information. A specific feature of this phenomenon is its emotional charge, which determines the speed of its spread and impact on the emotional and motivational-need-sphere of the individual, while suppressing the activity of the cognitive sphere, in particular, the ability to preserve the criticality of thinking, and causing nervous exhaustion.

From January 10 to May 8, 2020, more than 600 million tweets were posted on Twitter, of which 600,000 were randomly selected. An analysis of their reliability showed that $10 \%$ are disinformation [3]. Escola-Gascón, Marín, Rusiñol, \& Gallifa (2021) found that the ability to distinguish scientific information from pseudoscientific information predicts from 20 to $32 \%$ of psychological well-being, and according to the results of the study, residents of large cities find it more difficult to navigate the veracity of information, than rural residents, which is probably due to its redundancy in a large city as opposed to a rural area [4]. The negative impact of excess information was also confirmed in a study by Zhang, Zhang, Xiao, \& Zheng (2021), who found that an abundance of information on social networks and a low level of its quality increased respondents' fatigue [5]. Thus, the abundance of information requires a large amount of effort to process it, which leads to an increase in fatigue and, as a consequence, a decrease in people's criticism of the information received and the acceptance of unconstructive decisions.

According to Google Trends analysts, the word "death" in April 2020 reached its peak values in search queries and use in the web-space around the world, since 2004 (see Fig.1). Thus, a person in a lockdown was faced with the need to be in the web space (since it remained the only means of communication with the world, family and friends, work processes were transferred to the Internet, it also became one of the main ways to have fun), while he was faced with a reminder of death, triggering the action of the proximal defenses. As a result, some people began to show nihilistic behavior in the form of avoiding information about the coronavirus or hypochondriacal, resulting in excessive activity to resist infection.

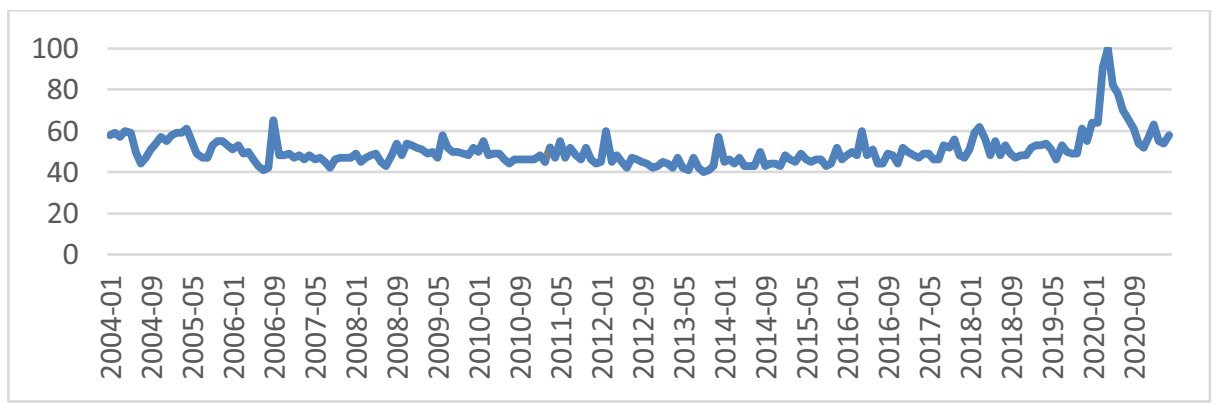

Fig. 1. The relative number of requests for the word "death" in relation to the total number of requests in the web-space around the world since 2004 according to Google Trends. Peak April 2020

The first behavior was discovered by Chinese colleagues, who found that the flood of information about the infection that hit the population led to an information overload, which led to the avoidance of obtaining further information. However, avoiding communication has been found to negatively impact adherence to preventive measures [6].

Feedback in the form of anxious behavior was found in a study by Garfin and colleagues (2020) [7]. The results of the study showed that the over-provision of information about coronavirus infection contributed to an increase in anxiety and stress levels in those who belonged to the categories of the population with a low risk of infection, which led to an overload of medical facilities, including due to hypochondriacal and anxiety reactions in the population. 
Alekhin \& Dubinina (2020) also emphasize the impact of information pressure on people by the media and social media, and denote it by the term "headline stress disorder" (literally - stress disorder connected with news headlines), which refers to mental adjustment disorders under the influence persistent emotionally charged news information" [8, p. 314]. The term was introduced by American authors after the 2016 presidential race, and in 2020 it may receive a more complete interpretation due to the wide representation of the empirical base, which may represent a large part of humanity.

Thus, the influence of the media on society in general, and the individual in particular, takes almost a paramount role in experiencing a pandemic due to the impact on the dynamics of the course of psychophysiological processes and the formation of complex forms of human behavior, which will be discussed below.

\subsection{Intergroup tension}

During the pandemic, people faced an indirect reminder of death in the form of countermeasures of the virus - masks, antiseptics, gloves, reminders of social distance, markings in public places. These indirect reminders trigger the action of distal defenses associated with the protection of one's own cultural picture of the world and a simultaneous increase in rejection of someone else's, aggression in response to encroachments in one's direction. The result of such tendencies is the aggravation of intercultural and interethnic relations, which brightly developed, for example, in the USA, France, Austria, on the basis of religious, cultural, national differences, including in the form of terrorist acts and destructive demonstrations. The consequences of these clashes are reflected to this day in the form of renaming institutions, revising cultural monuments and historical events, reevaluating the contribution of individual personalities to the historical process, national politics, and corporate ethics. A particular case of intergroup tension is the stigmatization of certain groups of the population, and the consequence is the dynamics of political preferences.

\subsection{Stigmatization of certain groups of the population}

Stigmatization in a pandemic situation has been personified in the form of two trends, which may be due to the different nature of the phenomenon. On the one hand, we could observe stigmatization due to stereotyping, when everything that was indirectly related to coronavirus infection was avoided. For example, members of the Asian race were severely stigmatized in Europe and the United States: Lee (2020) found that anxiety associated with coronavirus is positively correlated with avoidance of Chinese food and products [9]; Taiwanese avoid contact with Chinese and Japanese [10].

On the other hand, stigmatization manifested itself in the segregation of various population groups. So, due to the limited resources - medical personnel, technical equipment, medicines, ventilators - there was a restructuring of priorities in relation to population groups in need of support and assistance. Some of them faced difficulties in obtaining medical care - for example, people held in neuropsychiatric dispensaries, prisons, nursing homes [11]. Researchers note the high role of the media in shaping public opinion about the allocation of resources and stigmatization of certain population groups.

\subsection{Dynamics of political preferences}

The question of the influence of fear on the development of the political agenda and the management of public sentiment has long been reflected in the context of humanitarian studies. Scientists agree that fear acts as one of the most powerful tools for obtaining, 
realizing and retaining political power, forming public interests and transforming the value system. Vital and existential fears take on special significance here, and it is these fears that have become widespread during the pandemic. In this regard, the theory of managing the fear of death can provide explanations for what is happening in the political sphere of societies that have embarked on the fight against coronavirus infection.

In this case, two approaches to understanding political processes can be applied: the hypothesis of protecting the political picture of the world and the hypothesis of a conservative shift; both of these hypotheses describe the effect of distal protection to strengthen and protect the existing cultural picture of the world in conjunction with the struggle and rejection of alternative points of view and cultural pictures of the world. The first hypothesis focuses more on the polarization of society - conservatives are becoming more intolerant of representatives of other groups, and liberals are more inclined to accept alternative points of view. So, for example, 2020 was held under various slogans of protecting the rights of various groups of the population - representatives of different nationalities, sexual preferences, gender identifications and others. The second hypothesis is that in general, conservative orientations and values of support for the current government, strengthening of patriotic attitudes and rejection of external groups will increase in society. In addition, people in a situation of vital threat and the actualization of the fear of death are ready to sacrifice their own rights and freedoms for the sake of safety according to the Gallup Institute, in different countries the number of people ready for such victims has increased from $45 \%$ to $70 \%, 85 \%$, and in some countries - up to $93 \%$. Thus, in an emergency situation, first of all, political forces and support from the right-wing political spectrum grow. At the same time, a symbolic victory over death is possible with the help of some "hero", "the quintessence of cultural values concentrated in a specific figure" [12, p. 114]. Hence, the role of the charismatic type of leadership, focused on upholding patriotic values and the national idea, increases. All this leads to rallying around the state and an increase in the ratings of the current political leaders. So, in March 2020, the support ratings of D. Trump, B. Johnson, E. Macron, D. Conte increased, although not all of them managed to maintain their positions.

Summing up the political development of the countries involved in the fight against coronavirus infection, we can conclude that the pandemic and the actualization of the fear of death shape the political agenda, in particular, they cause the strengthening of conservative values, an increase in the activity of adherents of liberal points of view, contribute to temporary support of the current government, ensure the advancement of charismatic leaders who uphold patriotic values. Thus, existential fear and vital threat create fertile ground for manipulating public consciousness.

\subsection{Aggravation of the condition of people suffering from mental disorders, and the occurrence of such in people who have not previously suffered from them}

A number of scientists consider the fear of death as a transdiagnostic construct underlying many mental disorders and neurotic conditions: anxiety-phobic, depressive, obsessivecompulsive, eating disorders, panic attacks $[13,14]$. According to Google Trends analytics, the word "panic attack" in March-April 2020 reached its peak values in search queries and use in the web space of the whole world and Russia, in particular, since 2004. The constant reminder of death in the media caused the active work of the proximal defenses, which acquired inadequate forms in people who already suffered from mental disorders, or became the cause of their appearance. They differ from the adaptive behaviors required in a pandemic and recommended by health and government officials, and lead to disruption to adaptation. Such forms include, for example, washing hands for several hours, excessive 
use of antiseptics to damage the skin of the hands, hysterical reactions to an occasional symptom (coughing or coughing someone nearby), self-medication and self-prophylaxis with unproven methods, purchase of medications "just in case", constant tests and examinations despite the absence of symptoms [14]. The latter leads to a serious problem in the form of an overload of the health care system and impediments to the provision of assistance to those who really need help, and the procurement of medicines has created a serious shortage of those. Self-medication and self-prophylaxis have led to the widespread use of antibiotics in the form of self-prescription, often with non-compliance with the requirements for their use, which means undermining the functioning of the human immune system, the consequences of which we have yet to face.

It is also worth paying attention to the occurrence of addictive behavior in relation to information technology. Most of the processes we are used to have been transferred to an online format. In this case, we are talking about work, education, communication, shopping, leisure. Moreover, this became a necessary measure, and not a conscious choice of people. For young people in the UK, this turned into information overload, increased fatigue and an attempt to stop using social networks, but the fear of losing social connections did not allow this intention to materialize [15], the same data was obtained in Germany [16].

\subsection{Inadequate buying activity}

Buying activity also developed in two directions.

On the one hand, this is the acquisition of goods as a realization of the desire for symbolic immortality. A study by Dar-Nimrod (2012) showed that respondents were more likely to purchase items advertised immediately after clips or programs that featured death, compared to those who did not [17].

On the other hand, Bentall and colleagues (2021) explain the increase in purchasing activity as a desire to "stock up" by objective reasons such as income level, having children, as well as specific personality traits, including the neurotic spectrum - depression, anxiety, incredulity, paranoia. Analytical thinking skills have a slowing effect on "panic buying" [18].

And if in the first case the problem unfolds within a separate family, whose incomes are wasted in an inadequate attempt to leave a memory of themselves in the form of purchased things, then in the second case "panic buying" becomes massive and artificially creates a shortage of certain goods. This situation is reflected in the media - first in the form of sarcasm and humor over people who buy up certain goods in bulk, then resentment about the lack of goods grows, and then those who did not condemn such behavior begin to implement it themselves; Leung and colleagues (2021) described this phenomenon in a Twitter response to "panic buying" toilet paper [19]. Taylor (2021), Yuen, Wang, Ma, \& Li (2020) also highlight the role of the media in creating scarcity [20,21]. The result of such behavior is the development of compulsive manifestations, fraught with the development of a mental disorder [22].

\section{Discussion}

The pandemic of coronavirus infection has become an unprecedented case in human history, in connection with which it has spawned or highlighted a number of social phenomena, the explanation for which remains to be found. One of the means of explanation can be the theory of managing the fear of death. It can also provide a conceptual basis for developing a strategy for overcoming a pandemic situation through an adequate, constructive implementation of the mechanisms of proximal and distal protection. 
The studies above demonstrate various options for maladjustment due to the destructive action of defence mechanisms, the consideration of which can help in the further fight against coronavirus infection and its consequences. The same work can help to anticipate some aspects of human behavior in the emergency situation that humanity faced during a pandemic.

During the pandemic, the power of the mass-media and social media and their impact on society and decision-making, both as an individual and at the level of world politics, have been demonstrated. This poses a serious problem in identifying methods to minimize negative consequences, primarily the spread of panic and alarmism as a destructive strategy of behavior.

The colossal amount of content on coronavirus infection has been produced during the pandemic has highlighted two trends that still need to be addressed. On the one hand, there is a need for control on the part of media that provide an opportunity for the publication of information materials, their labeling as scientific or pseudoscientific information; on the other hand, there is an obvious lack among the population in the level of development of skills to determine the degree of scientific character of the information presented. This once again shows the need to develop critical thinking as a vital competence of a modern person and, probably, insufficient work of education systems in this area.

Decrease in criticism and harshness of judgments observed among the population due to threats to life and health, stressful economic situation, restrictions, abundance of information impose greater responsibility for the released official information. Here, its quality, reliability and argumentation, and volume, and formulation are important, in particular - the presence of positive rhetoric to reduce the degree of catastrophic situation and reduce panic. All this requires the development and preparation of a clear action plan for information coverage in the event of such an emergency.

\section{Conclusion}

Thus, the authors come to the following conclusions:

1. Information technologies and the media have a tremendous impact on society and become a source of threat to mental health and social well-being during emergencies due to the speed of dissemination of information and the action of socio-psychological mechanisms of infection, imitation, conformism and others;

2. The situation of a pandemic and a vital threat has actualized thanatic issues in the life of society in general and of an individual in particular. The fight against the awareness of one's own mortality is implemented with the help of protective mechanisms, which have taken a maladaptive nature in a pandemic situation (alarmism, infodemic, intergroup tension, stigmatization of certain groups of the population, a shift in political preferences, aggravation or emergence of mental disorders, inadequate purchasing activity), and information technologies strengthened their effect;

3. Terror management theory carries a great explanatory potential in the context of individual psychological and social phenomena that manifested themselves during the pandemic. Taking into account the action of the protective mechanisms of the psyche, unfolding in a situation of vital threat, can form the basis of a strategic action plan to combat the spread of coronavirus infection, its consequences, readiness for new emergency situations and their information coverage.

Obviously, with the end of the pandemic, the world will no longer be the same. Therefore, now it is extremely necessary to make every effort to explain the nature of those negative phenomena that have manifested themselves during this period in order to prevent them in the future, and to make the process of recovery and return to the "pre-pandemic" 
lifestyle as safe, constructive and environmentally friendly as possible for the individual, family, society, humanity in general.

\section{References}

1. J. Greenberg, S. Solomon, T. Pyszczynski, A. Rosenblatt, J. Burling, D. Lyon, E. Pinel, Journal of Personality and Social Psychology 63(6), 913-922 (1992) DOI doi.org/10.1037/0022-3514.63.6.913

2. WHO official website https://www.who.int/ru/news/item/23-09-2020-managing-thecovid-19-infodemic-promoting-healthy-behaviours-and-mitigating-the-harm-frommisinformation-and-disinformation

3. W. De Caro, European Journal of Public Health. Issue Supplement_5 30, (2020) doi.org/10.1093/eurpub/ckaa165.065

4. Á. Escolà-Gascón, F.X. Marín, J. Rusiñol, J. Gallifa, Psychiatry Res (2021) doi.org/10.1016/j.psychres.2020.113628

5. Z. Zhang, L. Zhang, H. Xiao, J. Zheng, Personality and Individual Differences (2021) doi 10.1016/j.paid.2021.110774

6. S. Song, X. Yao, N. Wen, Information Processing \& Management 58(1), (2021) doi.org/10.1016/j.ipm.2020.102407

7. D.R. Garfin, R.C. Silver, E.A. Holman, Health Psychology 39(5), 355-357 (2020) doi.org/10.1037/hea0000875

8. A.N. Alekhin, E.A. Dubinina, Arterial'naya Gipertenziya = Arterial Hypertension 26(3), 312-316 (2020) doi.org/10.18705/1607-419X-2020-26-3-312-316

9. S.A. Lee, Death Studies 44, 393-401 (2020). doi.org/10.1080/07481187.2020.1748481

10. C.Y. Lin, Social Health and Behavior 3, 1-2. (2020) doi 10.4103/SHB.SHB_11_20

11. G.A. Chaimowitz, C. Upfold, L.P. Géa, A. Qureshi, H.M. Moulden, M. Mamak, J.M.W. Bradford, Prog Neuropsychopharmacol Biol Psychiatry (2021) doi: 10.1016/j.pnpbp.2020.110150

12. D.A. Parenkov, K.E. Petrov, Journal of International Analytics 11(2), 109-121 (2020) doi.org/10.46272/2587-8476-2020-11-2-109-121

13. L. Iverach, R.G. Menzies, R.E. Menzies, Clinical Psychology Review 34, 580-593 (2014) doi.org/10.1016/j.cpr.2014.09.002

14. R.E. Menzies, R.G. Menzies, Cognitive Behaviour Therapist 13, e19 (2020) doi.org/10.1017/S1754470X20000215

15. H. Liu, W. Liu, V. Yoganathan, V.-S. Osburg, Technological Forecasting and Social Change 166, (2021). doi.org/10.1016/j.techfore.2021.120600

16. J. Brailovskaia, J. Margraf, Computers in Human Behavior 11, (2021) doi.org/10.1016/j.chb.2021.106720

17. I. Dar-Nimrod, Journal of Social Psychology 152, 199-211 (2012) doi.org/10.1080/00224545.2011.588273

17. R.P. Bentall, A. Lloyd, K. Bennett, R. McKay, L. Mason, J. Murphy, O. McBride, T.K. Hartman, J. Gibson-Miller, L. Levita, A.P. Martinez, T.V.A. Stocks, S. Butter, F. Vallières, P. Hyland, T. Karatzias, M. Shevlin, PLoS One 16(1), e0246339 (2021) doi.org/10.1371/journal.pone.0246339 
18. J. Leung, J.Y.C. Chung, C. Tisdale, V. Chiu, C.C.W. Lim, G. Chan, Int J Environ Res Public Health. Jan 27 18(3), 1127 (2021) doi.org/10.3390/ijerph18031127

19. S. Taylor, J Anxiety Disord. Mar. 78, $102364 \quad$ (2021) doi.org/10.1016/j.janxdis.2021.102364

20. K.F. Yuen, X. Wang, F. Ma, K.X. Li, Int J Environ Res Public Health 17(10), 3513 (2020) doi 10.3390/ijerph17103513

21. R.P. Rajkumar, Front Psychiatry. (2021) doi 10.3389/fpsyt.2021.652353 